\title{
Ebstein's anomaly and left proximal pulmonary artery stenosis complicated by pulmonary embolism: a case report
}

\author{
Snezana Bongard*, Marina Jurukovska, Irina Tonovska, Dushko Mihajlovski, Salis Tager \\ Clinical Hospital Acibadem — Sistina, Skopje, Republic of Macedonia
}

The clinical course of Ebstein's anomaly patients varies considerably. Commonly associated cardiac structural defects include: ASD, PFO, pulmonary stenosis and VSD.

We present a case of a 26-year-old patient admitted with dyspnea, exercise intolerance, epistaxis and tachycardia deteriorating for 4 months prior to admission. In a CT angiography performed prior to admission, a stenosis of the proximal left pulmonary artery was noted with a post-stenotic dilatation and a well developed bronchial circulation. A trans-thoracic echo upon admission showed a typical image of Ebstein's anomaly with the septal leaflet of the tricuspid valve displaced into the RV cavity, attached to a hypertrophied myocardium. Severe eccentric tricuspid regurgitation was present. Right heart catheterization measured a low pulmonary pressure of $30 \mathrm{mmHg}$. The catheter was blocked at the proximal left pulmonary artery. A CT angiography revealed a complete occlusion of the left pulmonary artery. In surgery, the septal leaflet of the tricuspid valve was dysplastic and non-functional with an abnormally high insertion of both the septal and posterior leaflets. The patient underwent pulmonary thrombo-endarterectomy, RVOT myotomy and tricuspid valve replacement with a mechanical valve ATS 31 $\mathrm{mm}$. Histologically, the excised leaflets contained fibrinoid necrosis. The postoperative course was uneventful and the patient was discharged on the $7^{\text {th }}$ postoperative day and is doing well since (two months).

We conclude that the patient underwent an acute event of pulmonary embolism with a background congenital pulmonary artery stenosis and Ebstein's anomaly. This case is significant for the unusual association of two rare congenital entities not known to be related.

KEYWORDS: Ebstein's anomaly, pulmonary artery stenosis, pulmonaly embolism.

CITATION: Cardiol Croat. 2013;8(9):302.

\section{Received: $14^{\text {th }}$ Aug 2013}

*Address for correspondence: Clinical Hospital Acibadem — Sistina, St. Skupi 5A, 1000 Skopje, Republic of Macedonia.

Phone: + 38972766525

E-mail: drmeskovska@yahoo.com

\section{Literature}

1. Cherry C, DeBord S, Moustapha-Nadler N. Ebstein's anomaly: a complex congenital heart defect. AORN J. 2009;89(6):1098-110.

2. Kilner PJ. Imaging congenital heart disease in adults. Br J Radiol. 2011;84 Spec No 3:S258-68.

3. Warnes CA. Adult congenital heart disease importance of the right ventricle. J Am Coll Cardiol. 2009;54:1903-10. 